\title{
man \\ A Double-Site Chemodosimeter for Selective Fluorescence Detection of a Nerve Agent Mimic
}

\author{
Xin Guo ${ }^{1}$, Chang-Xiang Liu ${ }^{1}$, Yuan Lu ${ }^{2}$, Ya-Wen Wang ${ }^{1, *(\mathbb{D} \text { and Yu Peng }} 1, * \mathbb{C}$ \\ 1 School of Life Science and Engineering, Southwest Jiaotong University, Chengdu 610031, China; \\ guoxin@my.swjtu.edu.cn (X.G.); lchx2020211799@my.swjtu.edu.cn (C.-X.L.) \\ 2 Chengdu Municipal Bureau of Economic and Information Technology, Chengdu 610229, China; \\ luyuan@lzu.edu.cn \\ * Correspondence: ywwang@swjtu.edu.cn (Y.-W.W.); pengyu@swjtu.edu.cn (Y.P.)
}

check for

updates

Citation: Guo, X.; Liu, C.-X.; Lu, Y.;

Wang, Y.-W.; Peng, Y. A Double-Site

Chemodosimeter for Selective

Fluorescence Detection of a Nerve

Agent Mimic. Molecules 2022, 27, 489.

https://doi.org/10.3390/

molecules27020489

Academic Editors: Adam C.

Sedgwick, Robert B. P. Elmes, Peter

Harvey and Xiao-Peng He

Received: 18 December 2021

Accepted: 11 January 2022

Published: 13 January 2022

Publisher's Note: MDPI stays neutral with regard to jurisdictional claims in published maps and institutional affiliations.

Copyright: (C) 2022 by the authors. Licensee MDPI, Basel, Switzerland. This article is an open access article distributed under the terms and conditions of the Creative Commons Attribution (CC BY) license (https:// creativecommons.org/licenses/by/ $4.0 /)$.

\begin{abstract}
A novel two-site chemodosimeter (SWJT-4) based on fluorescein skeleton to detect diethyl chlorophosphate (DCP) was designed and synthesized. It is a turn-on fluorescent probe for DCP with good selectivity and obvious color change in aqueous solution. Interestingly, the two oxime groups of SWJT-4 as dual response sites initiated different reactions with DCP to form a cyano group and an isoxazole ring, respectively. The corresponding mechanism was confirmed by ${ }^{1} \mathrm{H}$ NMR, MS and DFT calculation. Moreover, SWJT-4 could be used as a fluorescent test paper to detect DCP vapor.
\end{abstract}

Keywords: fluorescence; diethyl chlorophosphate (DCP); double-site; chemodosimeter

\section{Introduction}

Organophosphate nerve agents refer to a class of chemical substances composed of organophosphorus compounds (OPs). They have been widely used in pesticides and chemical warfare agents, such as parathion, systemic phosphorus, malathion, dimethoate, DDVP, tabun, sarin and soman [1,2]. These chemicals can result in a range of neurological symptoms such as headache, dizziness and agitation [3-6]. Organophosphorus compounds were used as a chemical weapon in war to threaten the safety of human life seriously. In a word, organophosphorus nerve agents are not only a potential threat of biochemical warfare, but also a usual weapon of terrorist organizations. Therefore, the detection of these substances by a convenient method is very necessary.

At present, the fluorescence analysis methods have attracted widespread attention due to their real-time monitoring, high selectivity, high sensitivity, low detection limit and so on. To obtain specific recognition of diethyl chlorophosphate (DCP), an organophosphate nerve agent mimic, some fluorescence probes were designed as chemodosimeters based on organic reaction [7-30]. Notably, DCP can phosphorylate with such probes including amino [7-9], hydroxyl [10-16], oxime [17-21] and pyridine [22-24] groups as the reaction sites. DCP can be reacted with a hydroxyl-ammonia $[25,26]$ or carboxyl-ammonia [27] group of probes to produce cyclization products as well. The different structures of the probe and the corresponding product lead to the changes in fluorescent signals. However, most probes for DCP are fluorescence ON-OFF responses [31-37]. In addition, several probes detect DCP in organic solution $[17,20,25,28]$, but a few probes detect DCP in aqueous solution (Table S1, Supplementary Materials) $[18,38,39]$. Therefore, the development of a turn-on fluorescent probe for DCP in an aqueous solution is still in high demand.

In our previous work, we synthesized a series of DCP probes based on ON-OFF fluorescent responses [40,41]. In the present work, a novel fluorescent probe SWJT-4 with two response sites was designed and synthesized for selective detection of DCP. It has good photochemical stability in an aqueous solution. The turn-on fluorescent responses could be achieved by tethering two oxime groups to a fluorescein skeleton. Moreover, SWJT-4 could be used to detect DCP vapor by a fluorescent test paper. 


\section{Results and Discussion}

\subsection{Design and Photoproperties of SWJT-4}

According to the Duff reaction, two aldehyde groups were formed at the ortho positions of two hydroxyl groups of fluorescein [42]. Two oxime groups as the recognition sites were then added to the fluorophore to construct SWJT-4 (Scheme 1). The C = N rotation in SWJT-4 would weaken the fluorescence. With the addition of DCP, an isoxazole or cyano group would be formed, which would inhibit the rotation of $\mathrm{C}=\mathrm{N}$ and therefore enhance the fluorescence. The corresponding ${ }^{1} \mathrm{H}$ and ${ }^{13} \mathrm{C}$ NMR spectra and ESI-MS of SWJT-4 are demonstrated in Figures S1-S3 (Supplementary Materials). In order to study its solvent effect on fluorescence properties of SWJT-4, five common organic solvents, namely acetone, methanol, tetrahydrofuran (THF), N,N-dimethyl formamide (DMF) and dimethyl sulfoxide (DMSO), were selected to test their performance under excitation at $520 \mathrm{~nm}$. As shown in Figure S4 (Supplementary Materials), SWJT-4 in DMSO has a longer emission wavelength. After the addition of DCP, the fluorescence intensity was enhanced clearly. Subsequently, the impact of pH on SWJT-4 was also studied (Figure S5, Supplementary Materials). SWJT-4 did not react with DCP under acidic conditions, and the best reaction condition was pH 7.0 to 8.0. Therefore, DMSO-HEPES $(1 / 1, v / v, \mathrm{pH} 7.4)$ buffer solution was determined as the optimal condition.
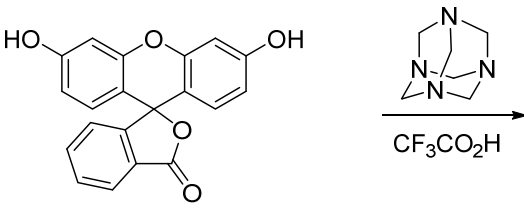

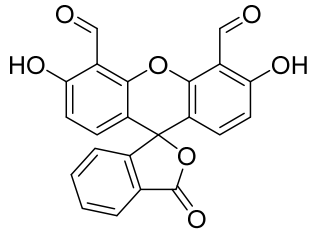

1

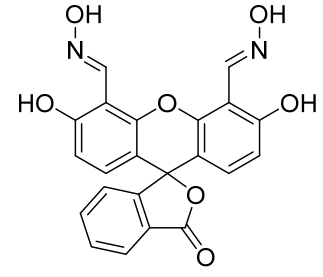

SWJT-4

Scheme 1. Synthesis of SWJT-4.

\section{Fluorescence Response of SWJT-4 to DCP}

As shown in Figure 1a, the UV-visible absorption spectrum of SWJT-4 exhibited prominent absorption at $522 \mathrm{~nm}$, which was attributed to the formation of intramolecular hydrogen bonds between the hydroxyl groups on fluorescein and the nitrogen atom on oxime, and the hydrogen bonds would enlarge the conjugation of the probe [43]. When DCP was added to the solution of the probe, the absorbance was blue-shifted to $508 \mathrm{~nm}$, which is the absorption of the ring-opening structure of fluorescein [44]. These results showed that the reaction occurred between SWJT-4 and DCP to break the intramolecular hydrogen bonds. The color of the solution changed from pink to pale yellow (Figure 1a, inset). For the fluorescence spectrum, under the excitation of $520 \mathrm{~nm}$, SWJT-4 showed weak emission at $557 \mathrm{~nm}(\Phi=5.7 \%)$ (Figure 1b). After the addition of DCP, the fluorescence was enhanced at $545 \mathrm{~nm}(\Phi=26.7 \%)$ with a slight blue-shift [45]. The fluorescence color of the solution was observed to turn chartreuse to green (Figure 1b, inset). These results showed that SWJT-4 was a turn-on fluorescent probe and could be used for the detection of DCP.

The fluorescence titration experiment of SWJT-4 was then studied. As shown in Figure 1c, the fluorescence intensity gradually increased with the increase in DCP. There was a good linear relationship between DCP concentration and the fluorescence intensity in the range of $0-140.0 \mu \mathrm{M}$ (Figure 1d). The detection limit was calculated as $53.0 \mathrm{nM}$ (Figure S6, Supplementary Materials), which was much lower than the reported lethal dose $(0.01 \mathrm{mg} / \mathrm{L})$ [46]. This result indicated that SWJT-4 had high sensitivity to DCP and could detect DCP at lower concentrations in an aqueous solution. Moreover, as shown in Figure S7 (Supplementary Materials), the recognition reaction finished within $100 \mathrm{~min}$ after the addition of DCP. The pseudo-first-order reaction constant $\left(k_{\mathrm{obs}}\right)$ was $5.37 \times 10^{-4} \mathrm{~s}^{-1}$. In order to verify the stoichiometry between the SWJT-4 and DCP, a Job plot analysis was performed (Figure S8, Supplementary Materials), which indicated that the ratio of SWJT-4 
and DCP was 1:2. By Benesi-Hildebrand equation of this binding mode (1:2), a linear line with good linearity was obtained, and the binding constant was $1.37 \times 10^{6} \mathrm{M}^{-2}$ (Figure S9, Supplementary Materials). These results were in good agreement with the stoichiometry between chemodosimeter and DCP.
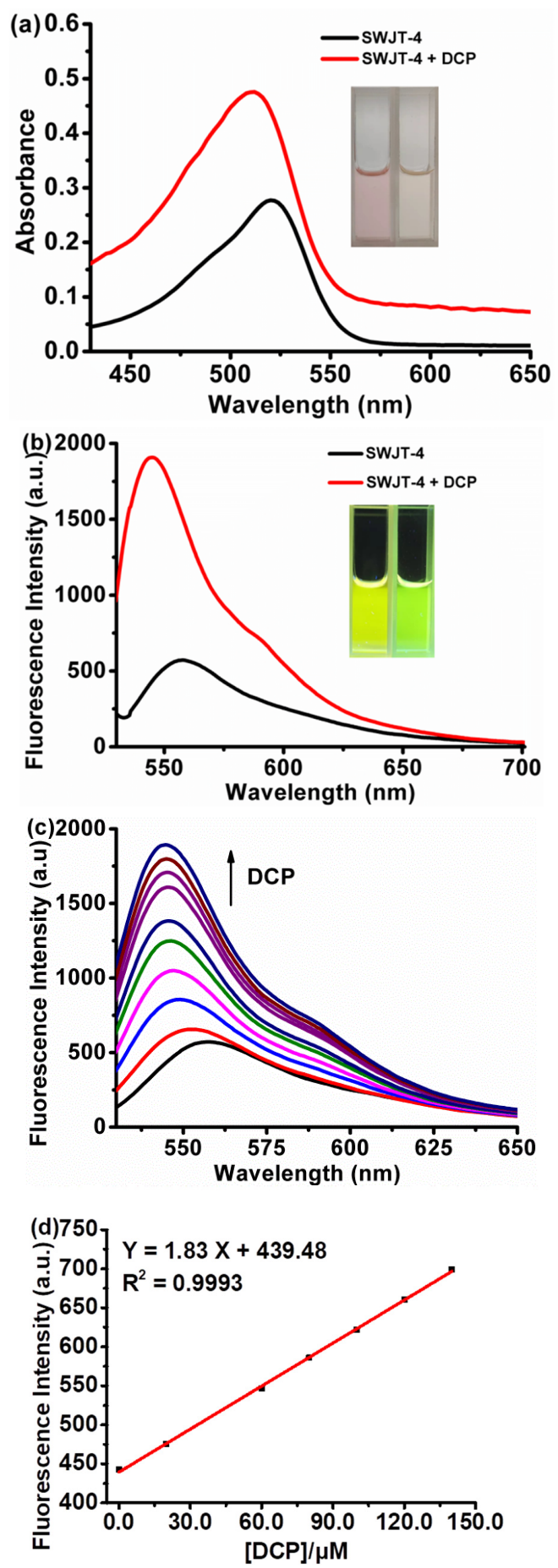

Figure 1. (a) The absorption spectrum of SWJT-4 $(10.0 \mu \mathrm{M})$ and SWJT-4 + DCP (1.0 mM) in DMSOHEPES (1/1, v/v, pH 7.4) buffer solution. Inset: the images of SWJT-4 and SWJT-4 after addition of DCP under visible light. (b) Fluorescence spectrum of SWJT-4 (10.0 $\mu \mathrm{M})$ and SWJT-4 + DCP (1.0 mM) in DMSO-HEPES (1/1, v/v, pH 7.4) buffer solution. Inset: the images of SWJT-4 and SWJT-4 after addition of DCP under ultraviolet light. (c) Fluorescence titrations of SWJT-4 (10.0 $\mu \mathrm{M})$ with different concentrations of DCP $(0-1000.0 \mu \mathrm{M})$; (d) Linear relationship between the fluorescence intensity of SWJT-4 $(10.0 \mu \mathrm{M})$ at $545 \mathrm{~nm}$ and the concentration of DCP $(0-140.0 \mu \mathrm{M})$. 


\subsection{Competition Experiments}

In order to investigate the plausible interference of other organophosphorus reagents or nerve agent mimics on the detection of DCP, phosphoric acid (PA), cyanomethyl diethyl phosphate (DCMP), cyanoyl diethyl phosphate (DCNP) and ethyl dichlorophosphate (DCEP) were selected to study the selectivity of SWJT-4 (Figure 2). With the addition of other phosphate-containing substances, the fluorescence intensity of SWJT-4 changed little. However, after the addition of DCP to the solution of SWJT-4, the fluorescence at $545 \mathrm{~nm}$ was significantly enhanced. These results clearly showed that the fluorescent probe SWJT-4 could recognize DCP effectively even in the presence of other war agent mimics.
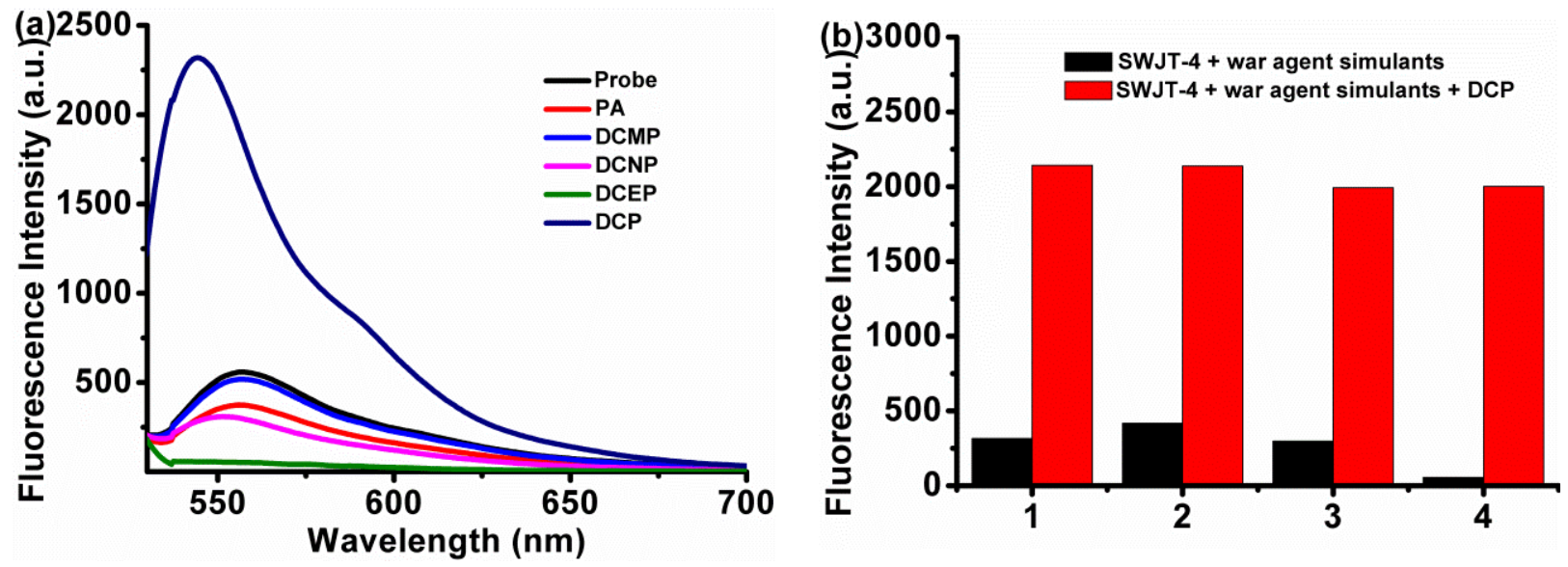

Figure 2. The fluorescence responses of (a) SWJT-4 $(10.0 \mu \mathrm{M})$ with different war agent simulants $(1.0 \mathrm{mM})$. From left to right: SWJT-4, phosphoric acid (PA), cyanomethyl diethyl phosphate (DCMP), cyanoyl diethyl phosphate (DCNP), ethyl dichlorophosphate (DCEP) and diethyl chlorophosphate (DCP); (b) SWJT-4 $(10.0 \mu \mathrm{M})$ with different war agent simulants $(1.0 \mathrm{mM})$ and DCP $(1.0 \mathrm{mM})$ in DMSO-HEPES (1/1, v/v, pH 7.4) buffer solution (1, phosphoric acid; 2 , cyanomethyl diethyl phosphate; 3, cyanoyl diethyl phosphate; 4, ethyl dichlorophosphate). Black bar: SWJT-4 + war agent simulants; red bar: SWJT-4 + war agent simulants + DCP.

\subsection{Response Mechanism}

In order to identify the reaction mechanism between SWJT-4 and DCP, ${ }^{1} \mathrm{H}$ NMR titration was performed. As shown in Figure 3a, the peaks at $11.90 \mathrm{ppm}$ and $11.10 \mathrm{ppm}$ belonged to the proton signals of two hydroxyl groups $\left(\mathrm{H}_{\mathrm{a}}\right)$ on oxime moieties and two hydroxyl groups $\left(\mathrm{H}_{\mathrm{b}}\right)$ on fluorescein in SWJT-4, respectively. The chemical shift of the proton $\left(\mathrm{H}_{\mathrm{c}}\right)$ of the aldoxime group was at $8.80 \mathrm{ppm}$. After the addition of DCP, the original signals $\mathrm{H}_{\mathrm{a}}$ and $\mathrm{H}_{\mathrm{b}}$ in the probe disappeared, and one aldoxime proton $\mathrm{H}_{\mathrm{c}}$ moved from 8.80 to $9.44 \mathrm{ppm}$ downfield. The above results indicated that different reactions occurred at the two reaction sites of SWJT-4 to form product 2. One oxime group reacted with one DCP to form the nitrile [47], and the other oxime group reacted with another DCP to form an isoxazole ring. Firstly, the hydroxyl group in the oxime attacked the phosphorus center of DCP to form phosphate oxime. Then, another hydroxyl group in the adjacent position of the oxime group could intramolecularly attack this generated intermediate, and the isoxazole ring was then formed through a release of phosphate moiety [48]. Meanwhile, the mixture of SWJT-4 and DCP was also characterized by ESI-MS, and the peak at $m / z$ 381.3 corresponding to product 2 was observed (Figure S10, Supplementary Materials).

\subsection{Computational Studies}

In order to further study the fluorescence responses of SWJT-4 with DCP and the influence of different solvent media on the absorption and emission, the B3LYP/6-31g method was conducted by Gaussian simulation (DFT) [49-51]. As shown in Figure 4, the main contribution for SWJT-4 was from HOMO - 2 to LUMO + 1 . The electron clouds of 
their HOMO - 2 orbital in SWJT-4 were distributed on one benzene ring of the xanthrene group and the adjacent oxime group. The electron clouds of the LUMO orbital of SWJT-4 were mainly distributed on the whole molecule instead. These results suggested the weak fluorescence of SWJT-4. As for product 2, the main contribution was HOMO - 2 to LUMO. The electron clouds of HOMO - 2 and LUMO orbitals were all mainly distributed in the xanthrene moiety, indicating the strong fluorescence character of $\mathbf{2}$. These results were very consistent with the fluorescence turn-on change on the detection of DCP using SWJT-4. Then, the absorption and emission of SWJT-4 were calculated in DMSO or in water (Figure S11, Supplementary Materials). As shown in Figure S11a,c (Supplementary Materials), the maximum emission wavelength of SWJT-4 in DMSO or in water was about $287 \mathrm{~nm}$ and the maximum absorption wavelength of SWJT-4 in DMSO or in water was $280 \mathrm{~nm}$ (Figure S11b,d, Supplementary Materials). Although these wavelengths greatly differ from the measured results, the results indicated that the solvent effect had almost no effect on absorption and emission spectra in different solvent media.

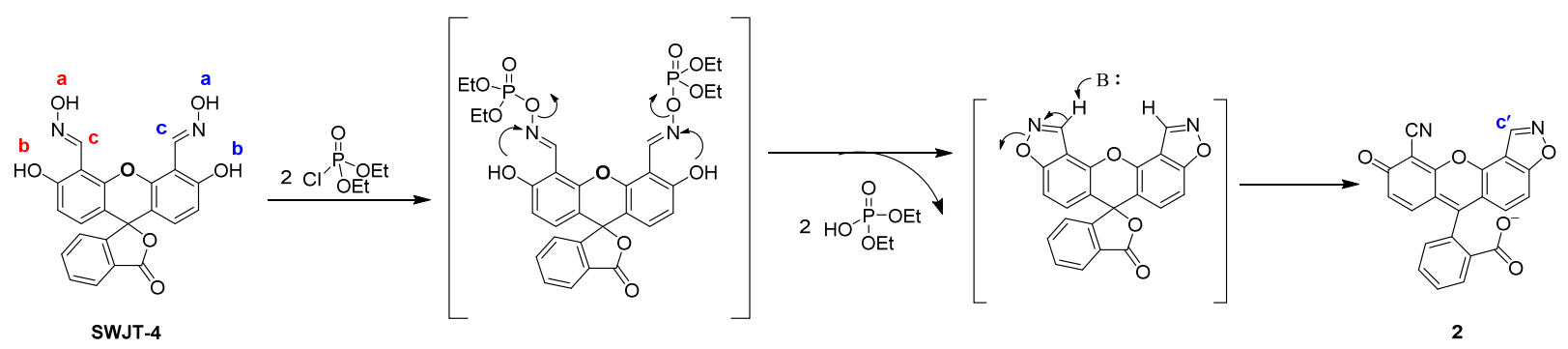

$\mathrm{H}_{\mathrm{c}} \mathrm{H}_{\mathrm{c}}$

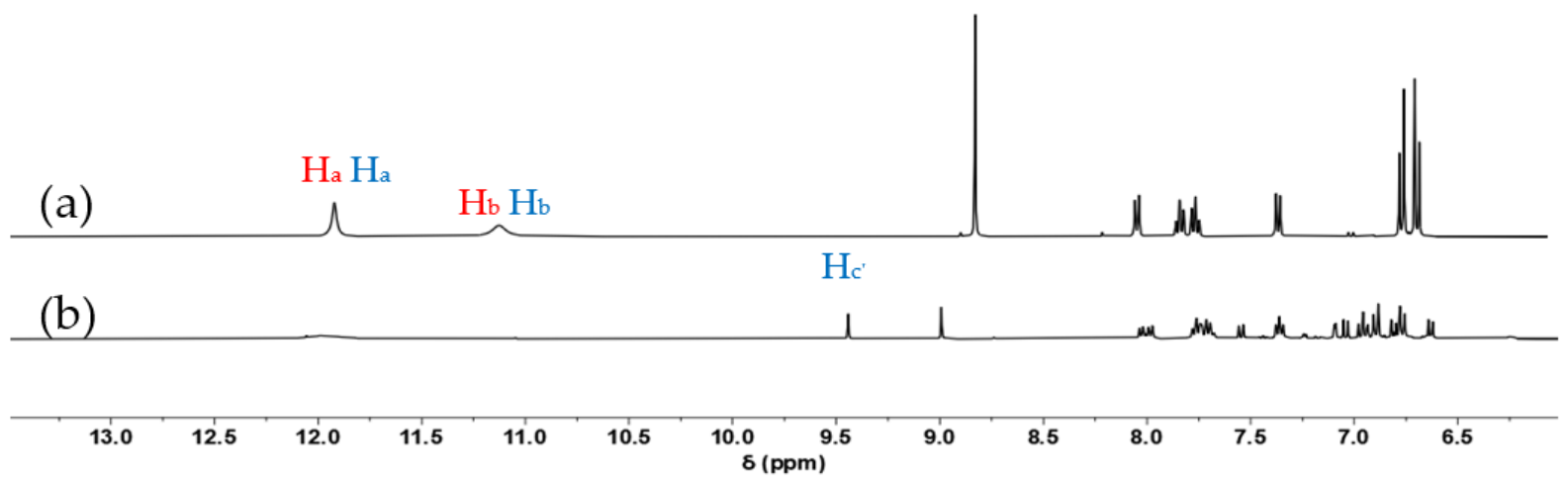

Figure 3. Partial ${ }^{1} \mathrm{H}$ NMR spectra of (a) SWJT-4 and (b) SWJT-4 + DCP in DMSO- $d_{6}$.

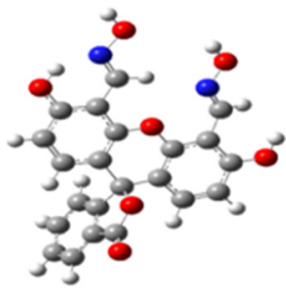

SWJT-4

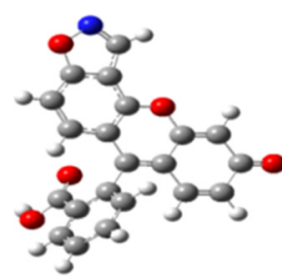

2

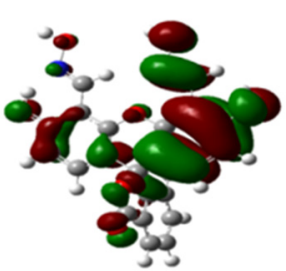

HOMO - 2

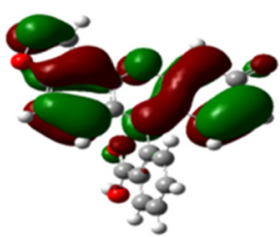

HOMO - 2

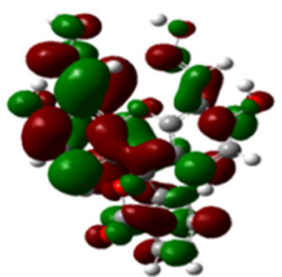

LUMO + 1

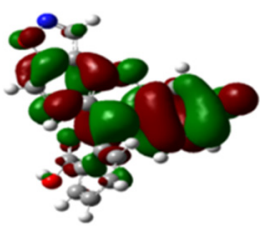

LUMO

Figure 4. The optimized structures and the molecular orbital plots of SWJT-4 and 2. 


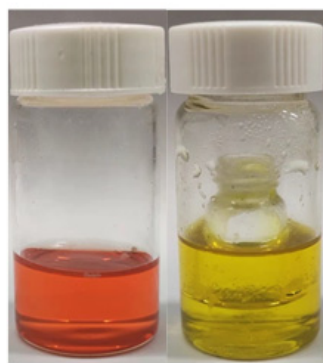

(a)

(b)

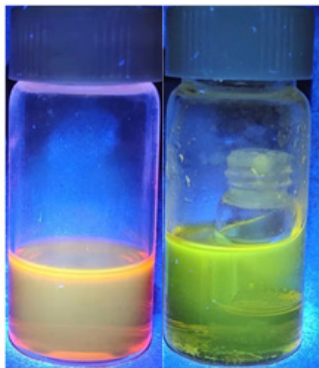

(c) (e)

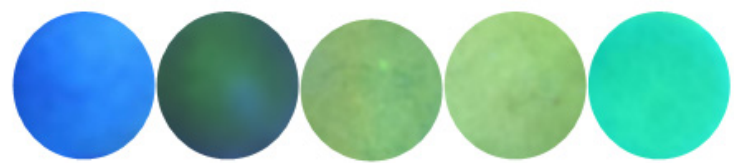

$(\mathbf{f})$

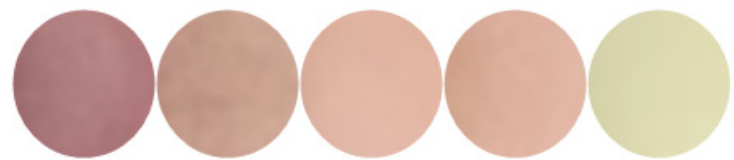

Figure 5. The color changes of (a,c) SWJT-4 (10.0 M) (DMSO-HEPES, 1/1, v/v, pH 7.4) solution and $(\mathbf{b}, \mathbf{d})$ exposure to DCP vapors under visible light or ultraviolet light. Paper sensors that visually detect different concentrations of DCP under ultraviolet light (e) and visible light (f). From left to right: $[\mathrm{DCP}]=0 \mathrm{mM}, 1.0 \times 10^{-3} \mathrm{mM}, 1.0 \times 10^{-2} \mathrm{mM}, 1.0 \times 10^{-1} \mathrm{mM}, 1.0 \mathrm{mM}$.

Moreover, the responses of SWJT-4 loaded on filter paper to different concentrations of DCP vapor were studied. With the increase in DCP concentration, the color of filter paper changed obviously under ultraviolet (Figure 5e) or visible light (Figure 5f), which was observed by the naked eye. The green color in paper sensors gradually increased under ultraviolet light (Figure 5e), and under visible light, the color of the paper sensors changed from pink to pale-yellow (Figure $5 \mathrm{f}$ ). These results showed that the probe can be used as a fluorescent test paper to detect DCP vapor and has potential application in the development of detection kits for DCP.

\section{Materials and Methods}

\subsection{Materials and Reagents}

Related materials, reagents and the detail of detection are described in the Supplementary Materials.

\subsection{Synthesis of Probe SWJT-4}

The compound $\mathbf{1}$ was synthesized according to a known procedure [42]. Hydroxylamine hydrochloride $(24.4 \mathrm{mg}, 0.62 \mathrm{mmol})$ was dissolved in ethanol $(3 \mathrm{~mL})$ and stirred at room temperature for $10 \mathrm{~min}$. Then compound $1(60.4 \mathrm{mg}, 0.16 \mathrm{mmol})$ was dispersed in $5 \mathrm{~mL}$ of ethanol and dripped into the above solution. The reaction mixture was stirred at room temperature for $2 \mathrm{~h}$. The organic solvent was removed by rotary evaporation, and the crude product was isolated by column chromatography (dichloromethane:methanol $=80: 1$ ) on silica gel to obtain the probe SWJT-4 (54.2 mg, yield $82.9 \%)$ as a pink solid. ${ }^{1} \mathrm{H}$ NMR $\left(400 \mathrm{MHz}\right.$, DMSO- $\left.d_{6}\right): \delta=11.90(\mathrm{~s}, 2 \mathrm{H}), 11.10(\mathrm{~s}, 2 \mathrm{H}), 8.80(\mathrm{~s}, 2 \mathrm{H}), 8.02(\mathrm{~d}, J=7.6 \mathrm{~Hz}, 1 \mathrm{H})$, $7.81(\mathrm{t}, J=7.5 \mathrm{~Hz}, 1 \mathrm{H}), 7.74(\mathrm{t}, J=7.0 \mathrm{~Hz}, 1 \mathrm{H}), 7.34(\mathrm{~d}, J=7.5 \mathrm{~Hz}, 1 \mathrm{H}), 6.74(\mathrm{~d}, J=8.8 \mathrm{~Hz}$, $2 \mathrm{H}), 6.67(\mathrm{~d}, J=8.8 \mathrm{~Hz}, 2 \mathrm{H}) .{ }^{13} \mathrm{C}$ NMR $\left(100 \mathrm{MHz}, \mathrm{DMSO}-d_{6}\right): \delta=169.0,159.1,152.5,149.0$, 145.6, 136.3, 130.8, 130.1, 126.4, 125.3, 124.5, 113.6, 110.2, 106.1, 82.6 ppm. ESI-MS: $m / z$ 419.1 $[\mathrm{M}+\mathrm{H}]^{+}$. 


\section{Conclusions}

In summary, the fluorescence changes of a novel fluorescent probe SWJT-4 for the detection of DCP based on the dual reaction site were explored. SWJT-4 showed good selectivity for DCP and the obvious color change in an aqueous solution. Notably, the two reaction sites in the probe also triggered different reaction types. Moreover, SWJT-4 could be used for DCP vapor detection and as fluorescent test paper to detect DCP.

Supplementary Materials: The following supporting information can be downloaded online: Table S1: Some reported work for the detection of DCP. Figures S1-Figure S3: Copies of ${ }^{1} \mathrm{H}_{1}^{13} \mathrm{C}$ NMR, ESI-MS spectra of SWJT-4. Figure S4: The changes of fluorescence in different solvents. Figure S5: The effect of $\mathrm{pH}$ on fluorescence intensity. Figure S6: The linear relationship between SWJT-4 and different concentrations of DCP. Figure S7: Time-dependent experiment of SWJT-4. Figures S8 and S9: Job's and Benesi-Hildebrand plots of SWJT-4 with DCP. Figure S10: ESI-MS spectrum of SWJT-4 + DCP. Figure S11: The fluorescence spectrum and absorption spectrum of SWJT-4 calculated by DFT in DMSO and water.

Author Contributions: Y.-W.W. conceived and designed the experiments; X.G. and C.-X.L. performed the experiments; X.G., C.-X.L., Y.L., Y.-W.W. and Y.P. analyzed the data; X.G., Y.-W.W. and Y.P. wrote the paper. All authors have read and agreed to the published version of the manuscript.

Funding: This work was supported by the National Natural Science Foundation of China (Nos. 21772078 and 22071200) and the Fundamental Research Funds for the Central Universities (Nos. 2682020CX55, 2682021ZTPY011 and XJ2021KJZK004) by MoE of China. We also thank the Science and Technology Department of Sichuan Province (2020JDRC0021).

Institutional Review Board Statement: Not applicable.

Informed Consent Statement: Not applicable.

Data Availability Statement: Not applicable.

Acknowledgments: We would like to thank the Analytical and Testing Center of Southwest Jiaotong University for the NMR test.

Conflicts of Interest: The authors declare no conflict of interest.

Sample Availability: Not applicable.

\section{References}

1. Walton, I.; Davis, M.; Munro, L.; Catalano, V.J.; Cragg, P.J; Huggins, M.T.; Wallace, K.J. A Fluorescent Dipyrrinone Oxime for the Detection of Pesticides and Other Organophosphates. Org. Lett. 2012, 14, 2686-2689. [CrossRef]

2. Muñoz-Quezada, M.T.; Lucero, B.A.; Iglesias, V.P.; Muñoz, M.P.; Cornejo, C.A.; Achu, E.; Baumert, B.; Hanchey, A.; Concha, C.; Brito, A.M.; et al. Chronic exposure to organophosphate (OP) pesticides and neuropsychological functioning in farm workers: A review. Int. J. Occup. Environ. Health 2016, 22, 68-79. [CrossRef]

3. Stone, R. How to defeat a nerve agent. Science 2018, 359, 23. [CrossRef]

4. Manco, G.; Porzio, E.; Suzumoto, Y. Enzymatic detoxification: A sustainable means of degrading toxic organophosphate pesticides and chemical warfare nerve agents. J. Chem. Technol. Biotechnol. 2018, 93, 2064-2082. [CrossRef]

5. Chen, L.; Wu, D.; Yoon, J. Recent Advances in the Development of Chromophore-Based Chemosensors for Nerve Agents and Phosgene. ACS Sens. 2018, 3, 27-43. [CrossRef]

6. Weis, J.G.; Swager, T.M. Thiophene-Fused Tropones as Chemical Warfare Agent-Responsive Building Blocks. ACS Macro Lett. 2015, 4, 138-142. [CrossRef]

7. Gharami, S.; Aich, K.; Das, S.; Patra, L.; Mondal, T.K. Facile detection of organophosphorus nerve agent mimic (DCP) through a new quinoline-based ratiometric switch. New J. Chem. 2019, 43, 8627-8633. [CrossRef]

8. Goswami, S.; Manna, A.; Paul, S. Rapid 'naked eye' response of DCP, a nerve agent simulant: From molecules to low-cost devices for both liquid and vapour phase detection. RSC Adv. 2014, 4, 21984-21988. [CrossRef]

9. Zhou, X.; Zeng, Y.; Liyan, C. A Fluorescent Sensor for Dual-Channel Discrimination between Phosgene and a Nerve-Gas Mimic. Angew. Chem. 2016, 128, 4807-4811. [CrossRef]

10. Xuan, W.; Cao, Y.; Zhou, J.; Wang, W. A FRET-based ratiometric fluorescent and colorimetric probe for the facile detection of organophosphonate nerve agent mimic DCP. Chem. Commun. 2013, 49, 10474-10476. [CrossRef]

11. Lu, Z.; Fan, W.; Shi, X.; Black, C.A.; Fan, C.; Wang, F. A highly specific BODIPY-based fluorescent probe for the detection of nerve-agent simulants. Sens. Actuators B Chem. 2018, 255, 176-182. [CrossRef] 
12. Sarkar, H.S.; Ghosh, A.; Das, S.; Maiti, P.K.; Maitra, S.; Mandal, S.; Sahoo, P. Visualisation of DCP, a nerve agent mimic, in Catfish brain by a simple chemosensor. Sci. Rep. 2018, 8, 3402. [CrossRef]

13. Singh, J.; Thakur, S.; Singh, R.; Kaur, V. Schiff base- $\mathrm{Zn}^{2+}$ ion combo as 'pick and degrade' probe for selected organophosphorus chemical weapon mimics and flame retardant analog: Detoxification of fruits and vegetables in aqueous media. Food Chem. 2020, 327, 127080. [CrossRef]

14. Jang, Y.J.; Mulay, S.V.; Kim, Y.; Jorayev, P.; Churchill, D.G. Nerve agent simulant diethyl chlorophosphate detection using a cyclization reaction approach with high stokes shift system. New J. Chem. 2017, 41, 1653-1658. [CrossRef]

15. Jang, Y.J.; Murale, D.P.; Churchill, D.G. Novel reversible and selective nerve agent simulant detection in conjunction with superoxide "turn-on" probing. Analyst 2014, 139, 1614-1617. [CrossRef]

16. Kim, T.I.; Maity, S.B.; Bouffard, J.; Kim, Y. Molecular Rotors for the Detection of Chemical Warfare Agent Simulants. Anal. Chem. 2016, 88, 9259-9263. [CrossRef]

17. Huo, B.; Du, M.; Shen, A.; Li, M.; Lai, Y.; Bai, X.; Gong, A.; Yang, Y. “Covalent-Assembly”-Based Fluorescent Probe for Detection of a Nerve-Agent Mimic (DCP) via Lossen Rearrangement. Anal. Chem. 2019, 91, 10979-10983. [CrossRef]

18. Ali, S.S.; Gangopadhyay, A.; Pramanik, A.K.; Guria, U.N.; Samanta, S.K.; Mahapatra, A.K. Ratiometric sensing of nerve agent mimic DCP through in situ benzisoxazole formation. Dyes. Pigm. 2019, 170, 107585. [CrossRef]

19. Cai, Y.C.; Li, C.; Song, Q.H. Selective and visual detection of a nerve agent mimic by phosphorylation and protonation of quinolin oximes. J. Mater. Chem. C 2017, 5, 7337-7343. [CrossRef]

20. Guria, U.N.; Maiti, K.; Ali, S.S.; Gangopadhyay, A.; Samanta, S.K.; Roy, K.; Mandal, D.; Mahapatra, A.K. An Organic Nanofibrous Polymeric Composite for Ratiometric Detection of Diethyl Chlorophosphate (DCP) in Solution and Vapor. ChemistrySelect 2020, 5 , 3770-3777. [CrossRef]

21. Kim, Y.; Jang, Y.J.; Mulay, S.V.; Nguyen, T.T.T.; Churchill, D.G. Fluorescent Sensing of a Nerve Agent Simulant with Dual Emission over Wide pH Range in Aqueous Solution. Chem. Eur. J. 2017, 23, 7785-7790. [CrossRef]

22. Kim, Y.; Jang, Y.J.; Lee, D.; Kim, B.S.; Churchill, D.G. Real nerve agent study assessing pyridyl reactivity: Selective fluorogenic and colorimetric detection of Soman and simulant. Sens. Actuators B 2017, 238, 145-149. [CrossRef]

23. Cai, Y.C.; Li, C.; Song, Q.H. Fluorescent Chemosensors with Varying Degrees of Intramolecular Charge Transfer for Detection of a Nerve Agent Mimic in Solutions and in Vapor. ACS Sens. 2017, 2, 834-841. [CrossRef]

24. Huang, S.; Wu, Y.; Zeng, F.; Sun, L.; Wu, S. Handy ratiometric detection of gaseous nerve agents with AIE-fluorophore-based solid test strips. J. Mater. Chem. C 2016, 4, 10105-10110. [CrossRef]

25. Wu, W.H.; Dong, J.J.; Wang, X.; Li, J.; Sui, S.H.; Chen, G.Y.; Liu, J.W.; Zhang, M. Fluorogenic and chromogenic probe for rapid detection of a nerve agent simulant DCP. Analyst 2012, 137, 3224-3226. [CrossRef]

26. Barba-Bon, A.; Costero, A.M.; Gil, S.; Harriman, A.; Sancenón, F. Highly Selective Detection of Nerve-Agent Simulants with BODIPY Dyes. Chem. Eur. J. 2014, 20, 6339-6347. [CrossRef]

27. Hu, X.X.; Su, Y.T.; Ma, Y.W.; Zhan, X.Q.; Zheng, H.; Jiang, Y.-B. A near infrared colorimetric and fluorometric probe for organophosphorus nerve agent mimics by intramolecular amidation. Chem. Commun. 2015, 51, 15118-15121. [CrossRef]

28. So, H.S.; Angupillai, S.; Son, Y.A. Prompt liquid-phase visual detection and low-cost vapor-phase detection of DCP, a chemical warfare agent mimic. Sens. Actuators B 2016, 235, 447-456. [CrossRef]

29. Mahapatra, A.K.; Maiti, K.; Manna, S.K.; Maji, R.; Mondal, S.; Das Mukhopadhyay, C.; Sahoo, P.; Mandal, D. A cyclization-induced emission enhancement (CIEE)-based ratiometric fluorogenic and chromogenic probe for the facile detection of a nerve agent simulant DCP. Chem. Commun. 2015, 51, 9729-9732. [CrossRef] [PubMed]

30. Goswami, S.; Das, S.; Aich, K. Fluorescent chemodosimeter based on spirobenzopyran for organophosphorus nerve agent mimics (DCP). RSC Adv. 2015, 5, 28996-29001. [CrossRef]

31. Patra, L.; Ghosh, P.; Das, S.; Gharami, S.; Murmu, N.; Mondal, T.K. A selective fluorogenic chemosensor for visual detection of chemical warfare reagent mimic diethylchlorophosphate. J. Photochem. Photobiol. A Chem. 2020, 388, 112188. [CrossRef]

32. Heo, G.; Manivannan, R.; Kim, H.; Son, Y.A. Liquid and gaseous state visual detection of chemical warfare agent mimic DCP by optical sensor. Dyes. Pigm. 2019, 171, 107712. [CrossRef]

33. Ali, S.S.; Gangopadhyay, A.; Pramanik, A.K.; Samanta, S.K.; Guria, U.N.; Manna, S.; Mahapatra, A.K. Real time detection of the nerve agent simulant diethylchlorophosphate by nonfluorophoric small molecules generating a cyclization-induced fluorogenic response. Analyst 2018, 143, 4171-4179. [CrossRef] [PubMed]

34. Fu, Y.; Yu, J.; Wang, K.; Liu, H.; Yu, Y.; Liu, A.; Peng, X.; He, Q.; Cao, H.; Cheng, J. Simple and Efficient Chromophoric-Fluorogenic Probes for Diethylchlorophosphate Vapor. ACS Sens. 2018, 3, 1445-1450. [CrossRef] [PubMed]

35. Suhasini, R.; Karpagam, R.; Thirumoorthy, K.; Thiagarajan, V. “Turn-on" unsymmetrical azine based fluorophore for the selective detection of diethylchlorophosphate via photoinduced electron transfer to intramolecular charge transfer pathway. Spectrochim. Acta A Mol. Biomol. Spectrosc. 2021, 263, 120206. [CrossRef]

36. Zhang, S.; Zhou, C.; Yang, B.; Zhao, Y.; Wang, L.; Yuan, B.; Li, H. Rhodamine phenol-based fluorescent probe for the visual detection of GB and its simulant DCP. New J. Chem. 2021, 45, 7564-7570. [CrossRef]

37. Zheng, P.; Cui, Z.; Liu, H.; Cao, W.; Li, F.; Zhang, M. Ultrafast-response, highly-sensitive and recyclable colorimetric/fluorometric dual-channel chemical warfare agent probes. J. Hazard Mater. 2021, 415, 125619. [CrossRef]

38. Kim, H.J.; Jang, S.; Ren, W.X.; Bartsch, R.A.; Sohn, H.; Kim, J.S. Imine-functionalized, turn-on fluorophore for DCP. Sens. Actuators B 2011, 153, 266-270. [CrossRef] 
39. Ali, S.S.; Gangopadhyay, A.; Maiti, K.; Mondal, S.; Pramanik, A.K.; Guria, U.N.; Uddin, M.R.; Mandal, S.; Mandal, D.; Mahapatra, A.K. A chromogenic and ratiometric fluorogenic probe for rapid detection of a nerve agent simulant DCP based on a hybrid hydroxynaphthalene-hemicyanine dye. Org. Biomol. Chem. 2017, 15, 5959-5967. [CrossRef]

40. Khan, M.S.J.; Wang, Y.W.; Senge, M.O.; Peng, Y. Sensitive fluorescence on-off probes for the fast detection of a chemical warfare agent mimic. J. Hazard. Mater. 2018, 342, 10-19. [CrossRef]

41. Feng, X.; Wang, Y.; Feng, W.; Peng, Y. Development of BINOL-Si complexes with large stokes shifts and their application as chemodosimeters for nerve agent. Chin. Chem. Lett. 2020, 31, 2960-2964. [CrossRef]

42. Xiong, X.; Song, F.; Sun, S.; Fan, J.; Peng, X. Red-Emissive Fluorescein Derivatives and Detection of Bovine Serum Albumin. Asian J. Org. Chem. 2013, 2, 145-149. [CrossRef]

43. Zhao, L.; Dong, X.T.; Zhang, S.T.; Chen, Q. Crystal structure of 1-(4-\{[(E)-5-bromo-2-hydroxybenzylidene]-amino\} phenyl) ethanone oxime, $\mathrm{C}_{15} \mathrm{H}_{13} \mathrm{BrN}_{2} \mathrm{O}_{2}$. Z. Kristallogr. NCS 2012, 227, 101-102. [CrossRef]

44. Sjöback, R.; Nygren, J.; Kubista, M. Absorption and fluorescence properties of fluorescein. Spectrochim Acta A Mol. Biomol. Spectrosc. 1995, 51, L7-L21. [CrossRef]

45. Melhuish, W.H. Quantum efficiencies of fluorescence of organic substances: Effect of solvent and concentration of the fluorescent solute. J. Phys. Chem. 1961, 65, 229-235. [CrossRef]

46. Sadik, O.A.; Land, W.H., Jr.; Wang, J. Targeting Chemical and Biological Warfare Agents at the Molecular Level. Electroanalysis 2003, 15, 1149-1159. [CrossRef]

47. Lee, H.; Kim, H.-J. Novel fluorescent probe for the selective detection of organophosphorous nerve agents through a cascade reaction from oxime to nitrile via isoxazole. Tetrahedron 2014, 70, 2966-2970. [CrossRef]

48. Radić, Z.; Dale, T.; Kovarik, Z.; Berend, S.; Garcia, E.; Zhang, L.; Amitai, G.; Green, C.; Radić, B.; Duggan, B.M.; et al. Catalytic detoxification of nerve agent and pesticide organophosphates by butyrylcholinesterase assisted with non-pyridinium oximes. Biochem. J. 2013, 450, 231-242. [CrossRef]

49. Lee, C.; Yang, W.; Parr, R.G. Development of the Colle-Salvetti correlation-energy formula into a functional of the electron density. Phys. Rev. B 1988, 37, 785-789. [CrossRef] [PubMed]

50. Becke, A.D. A new mixing of Hartree-Fock and local density-functional theories. J. Chem. Phys. 1993, 98, 1372-1377. [CrossRef]

51. Bauernschmitt, R.; Ahlrichs, R. Treatment of electronic excitations within the adiabatic approximation of time dependent density functional theory. Chem. Phys. Lett. 1996, 256, 454-464. [CrossRef] 